\title{
The Division and Size of Gains from Liberalization in Service Networks
}

Keshab Bhattarai and John Whalley

CSG R Working Paper No. 03/ 98

March 1998
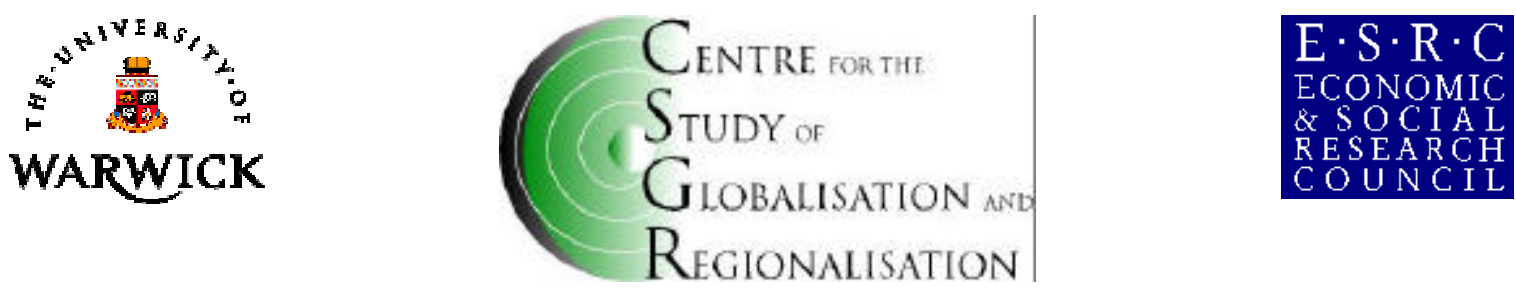

Centre for the Study of G lobalisation and Regionalisation (CSG R), University of Warwick, Coventry CV4 7AL, United-Kingdom. URL: http://www.warwick.ac.uk/fac/soc/CSGR 


\title{
The Division and Size of Gains from Liberalization in Service N etworks.
}

Bhattarai, Keshab and John Whalley, ${ }^{1}$

University of Warwick; Universities of Warwick and Western Ontario and NBER

CSG R Working Paper No. 03/ 98, March 1998

\begin{abstract}
:
This paper emphasizes the different nature of cross border liberalization in network related services, such as telcoms, compared to liberalization in goods. In the presence of network externalities, it argues that if two disjoint country service networks involving a small and large country are connected as part of international liberalization, the per capita gain for the small country from access to a large network will be large, and the per capita gain for the large country will be small. Benefits of liberalization in network related services, unlike goods, are more likely to be approximately equally divided between large and small countries than is true of trade in goods, where benefits accrue disproportionately to the small country. We also argue that non-cooperation in network related services trade may involve more extreme retaliation than suggested for trade in goods from the optimal tariff literature, so that relative to a non-cooperative outcome, gains from liberalization in network related services become larger than from liberalization in goods. An empirical implementation of global telcoms liberalization for the US, Europe, Canada and the Rest of the World using the framework developed in the paper shows larger gains to larger regions, consistent with the theme of the paper that goods and services liberalization differ.
\end{abstract}

Keywords: trade in services, network externality, trade in goods, Nash equilibrium

JEL Classification: D58,D62, F13

Address for correspondence:

Department of Economics

University of Warwick

Coventry CV4 7AL, United Kingdom

1 This paper has been prepared for the meetings of the Royal Economic Society, to be held at Warwick March 30- Apr 2, 1998. Earlier versions of this paper were presented at the Universities of Copenhagen and Western Ontario. Bhattarai and Whalley acknowledge financial support from the ESRC under an award for a project on General Equilibrium Modeling of UK Policy Issues. 


\section{The Division and Size of Gains from Liberalization in Service Networks}

\section{Introduction}

Here we discuss the cross border liberalization of flows of network related services such as telecoms, suggesting that both the division of the gains from liberalization between countries and the size of such gains is likely to be different from the case of trade in goods when tariff barriers are removed at the border. In the network related services case, no cross border payment for services is made since senders (callers) pay fully for services (messages), but cross border welfare effects of liberalization still occur. As prices for international calls are lowered, both senders and receivers of messages (calls) benefit. The addition of a new subscriber to a network confers an externality on existing subscribers who receives calls at no charge, since callers pay the full cost of calls. We model such effects as generated by preferences in which individual utility is a function not only of their own consumption of network related services, but also the consumption of others within the network. We then examine the effects of liberalization across country networks ${ }^{2}$. We make no explicit reference to the sharp reduction in international call rates in recent years ${ }^{3}$, even though these are a key part of the environment within which liberalization is now occuring.

We first consider a simple two good two-country case involving network-related services and other goods, in which the two countries have different numbers of consumers. If we model liberalization as the joining of two previously disjoint country networks into one combined cross country network, consumers in the smaller country receive a larger per capita gain than those in the larger country due to the network externalities, since these arise from gaining access to a larger network. Country size and the per capita benefit of access to the other country's network tend to offset each other in determining the division of the gains from liberalization, suggesting that the country gains from cross- border network service

\footnotetext{
2 See Katz and Shapiro $(1985,1986)$ for the initial constribution to this area. They apply network externalities to industrial organization structure, and the incentives to capture markets by the design of the network. Later contributions include Economides (1996), Liebowitz and Margolis (1994), and Choi (1994). Harris (1995) discusses the application to trade, but in a different framework from here.

${ }^{3}$ See the discussion of this in Cairncross's (1997) recent book "The Death of Distance".
} 
liberalization can be of similar (absolute) size. This is opposite to the case of trade in goods where the benefits of liberalization accrue disproportionately to the smaller country (in the limiting case, a small open price taking economy receives all the gains from its own trade liberalization).

We first construct an example in which the country gains from liberalization are of equal absolute size in the two countries (in money metric terms). We then show how it is possible to change preference and other model parameters so that larger gains accrue to the larger (rather than the smaller) country, or vice versa.

We also show how, in an alternative formulation with two types of network related services (international and domestic), it is possible to capture price based substitution effects between service categories. This allows us to model network related service trade liberalization as the removal of barriers to international services (which have cross-country network externality effects), rather than simply the joining of two disjoint networks. Using this alternative formulation, we again show that the absolute size of gains can be larger or smaller for the large (or small) country, depending upon the parameter specification used in the model.

We next turn to the issue of the size of the gains from liberalization of network related services. We characterize inter-country network service interactions as involving service delivery along a joined network, but in ways which, in principle, give each of the two governments in the origin and destination countries the power to tax the same transaction ${ }^{4}$. Phone calls made from, say, the US to India can be regulated or taxed by both governments as messages are either sent or delivered. We evaluate non-cooperative international retaliatory outcomes involving service barrier retaliation in this case, measuring the gains from liberalization by comparing free trade and non-cooperative Nash policy outcomes.

A cross country policy game in a service network reveals three key differences relative to the traditional Nash equilibrium tariff policy game in goods due to Johnson (1954) and Gorman (1957). One is the use of instruments (taxes) by both countries on each bilateral service flow; another is the absence of any restriction that two way service flows be balanced

\footnotetext{
${ }^{4}$ In practice, various sharing agreements between origin and destination countries operate. See ITU (1994) pp. 27-29 for a discussion for how these apply.
} 
in value terms as the services do not involve any cross country payment (unless taxed by the other government). The third is that inter-country flows along networks can be, and frequently are, unbalanced (more calls from the US to India, than from India to the US). As a result, both governments can have an incentive to charge high taxes in the Nash equilibrium if they can make the first charge on the appropriate bilateral service flow. We find that relative to a non-cooperative Nash outcome, gains from liberalization of network related services are typically larger than gains from liberalization in goods trade in models made comparable in the sense that the service flow parameter values now apply to different goods instead of services.

Finally, we apply our framework to global telecom liberalization in a model covering the EU, the US, Canada, and the Rest of the World, and calibrated to 1991 data. Data on call volumes and pricing is drawn from the World Telecommunication Development Report, and is supplemented by GDP and other data from the World Development Report. Liberalization yields gains larger in size for large (rather than small) regions; consistent with the theme of paper of the differences in liberalization between goods and services.

In concluding, we suggest that our analysis has three implications. The first is that the benefits of liberalization in network related services, unlike for goods, are more likely to be approximately equally divided between countries than is true of trade in goods, and this can occur independently of the size of the countries and the number of residents in each. The second is that non-cooperation in network related services trade may involve extremes of retaliation which go beyond even those suggested for goods trade in the optimal tariff literature, and so the gains from liberalization may be larger in network related services than in goods. The third is the large potential size of welfare gains from trans-border liberalization where network externality effects rather than conventional gains from trade apply. The broader implication is the seemingly different nature of cross border liberalization in network related services compared to liberalization in goods. 


\section{Network Externalities and the Division of Gains from Liberalization in a Simple Network Service Model}

We first consider a world consisting of two countries, each of which has a fixed endowment of resources which, in turn, can be used for producing goods or network related services. Services are consumed via a network, and involve no cross border payment, since services are purchased and consumed by senders of messages along the network ${ }^{5}$. They directly enter the sender's utility function as an argument; but they also provide utility to the receiver, and hence messages sent by others also appear in the utility function of the receiver. It is this feature which generates network externalities, since service recipients make no payment for incoming messages (calls) even though they receive a welfare benefit. The word externality in such situations denotes a consumption to consumption externality in the sense of Meade (1952); here the physical interdependence via message flows to recipients is not appropriately priced.

We use a transformation frontier to describe the technology which allows goods and services in each country to be produced from resource endowments,

$$
Y_{n}=F_{n}\left(G_{n}, S_{n}\right) \quad(\mathrm{n}=1,2)
$$

where $Y_{n}$ is the fixed resource endowment, $G_{n}$ is goods production, and $S_{n}$ is services production in country $n$.

$\mathrm{W}_{\mathrm{n}}$, the value of production of goods and services in country $\mathrm{n}$ is given by

$$
W_{n}=P_{g} G_{n}+P_{n}^{s} S_{n}
$$

where $P_{g}$ is the common cross country price of goods, and $P_{n}^{S}$ is the price of network related services in country n. No direct international trade in services occurs; senders pay for such services in their country of origin, and the prices of services can thus differ between the countries. The transformation frontier (1), along with (2), yields an implicit supply function for goods and services in each country.

\footnotetext{
5 Much of service activity, as Melvin (1989) has pointed out, is concerned with intermediation through time and/or space. Network related services not only capture activity in telecommunications, but also transportation services where recipients of shipments receive benefits while shipment costs are fully paid by the shipper. They seem not to cover inter-temporal intermediation, such as financial services, which involves intermediaries bringing together agents in order to transact.
} 
We assume that there are $T_{1}$ households in country 1 , and $T_{2}$ in country 2. Each household in each country derives utility directly from consumption of goods and from sending messages along the network (services). When connected to a service network, households also receive additional utility benefits from the services consumed by others in home and foreign countries, since they are the recipients of messages. We assume such benefits are proportional to the total volume of messages sent along the network; since as the total message volume expands so does the potential number of callers that could be in contact with any particular recipient.

We use a utility function to describe the preferences of each household. In this, ST, the total number of calls made along the relevant network, enters multiplicatively with a constant $\lambda^{6}$ which we, for now, take to be common to all individuals,

$$
U_{n}^{h}=\lambda \cdot S T \cdot U_{n}^{h}\left(G_{n}^{h}, S_{n}^{h}\right)
$$

The subscript $\mathrm{n}$ refers to countries and the superscript $\mathrm{h}$ to households in a country; $\mathrm{U}$ is utility, $\mathrm{G}$ is consumption of goods, and $\mathrm{S}$ is consumption of network related services. $S T$ is total consumption of network related services by all the households in the relevant network; the domestic network when networks are disjoint, or the international network when they are linked. In this formulation, the network externality impacts directly on household utility when there is an expansion in the service network to include both home and foreign countries.

We assume, for simplicity, that each household in each country receives a fixed share of the economy wide income

$$
I_{n}^{h}=\theta_{n}^{h} W_{n}
$$

where $I_{n}^{h}$ denotes income for household $\mathrm{h}$ in country $\mathrm{n}$, and $\sum_{h} \theta_{n}^{h}=1 ; \theta_{n}^{h} \geq 0$. This income is spent on purchasing goods and network related services. Each household budget constraint implies that

$$
I_{n}^{h}=P_{g} G_{n}^{h}+P_{n}^{S} S_{n}^{h}
$$

\footnotetext{
${ }^{6}$ The value of $\lambda$ determines the strength of the network externality effect. Having ST enter multiplicatively in this way also indicates that it is the potential number of other households in the network that might contact an individual household, rather than the expected number of calls actually received, that yields the external effect. A treatment based on the expected number of calls can also be accommodated within this framework.
} 
Demands for goods and services by each household are obtained from maximization of the utility function (3) subject to the household budget constraint (5).

As no direct trade in $\mathrm{S}$ takes place in this model, in equilibrium the market for goods and services clears in each country; i.e.

$$
\begin{aligned}
& G_{n}=\sum_{h} G_{n}^{h} \\
& \text { and } \\
& S_{n}=\sum_{h} S_{n}^{h}
\end{aligned}
$$

and arbitrage ensures the common price across countries for goods. In equilibrium, goods and services prices are thus such that country demands for goods and services match their domestic supply.

We can consider the effects of liberalization involving a joining of the two previously disjoint country service networks using this framework. In this case, the ST term in preferences refers to the combined service consumption across the two countries, rather than the two separate country service consumptions. As only the externality term in preferences changes, when liberalization occurs in this simple case there are no real effects from liberalization; prices and quantities of both goods and services within countries remain the same; only utility changes.

If the utility function (1) is linear homogenous, rather than only homothetic, the welfare implications of liberalization in this case are especially easy to analyze. As noted in Shoven and Whalley (1992), with linear homogenous preferences the Hicksian compensating variation measure of welfare change between equilibria is given by

$$
C V^{h}=\frac{U_{N}^{h}-U_{0}^{h}}{U_{N}^{h}} \cdot I_{N}^{h}
$$

where $U_{N}^{h}$ and $U_{0}^{h} \quad$ refer to the old and new utility levels for household h, and $I_{N}^{h}$ is the income of household $\mathrm{h}$ in the new (post change) equilibrium ${ }^{7}$.

\footnotetext{
${ }^{7}$ Alternatively Hicksian equivalent variation measures can be used, which in this case are $E V^{h}=\frac{U_{N}^{h}-U_{0}^{h}}{U_{0}^{h}} I_{0}^{h}$
} 
Because price and quantities do not change between equilibria, and because the term ST is multiplicative in utility from goods and own services, each household's compensating variation can be written as

$$
C V^{h}=\frac{S T^{N}-S T^{0}}{S T^{N}} \cdot I_{N}^{h}
$$

where the $\lambda$ terms cancel, and $\mathrm{ST}^{\mathrm{N}}$ and $\mathrm{ST}^{0}$ denote the aggregate service consumption values relevant for household $\mathrm{h}$ in the new and base period (original) equilibria. $I_{h}^{N}$ is household $\mathrm{h}$ new period equilibrium income.

If preferences are identical across the households in each country, the total welfare impact in the two countries, $T C V^{1}$ and $T C V^{2}$, can be written as

$$
\begin{aligned}
T C V^{1} & =W_{1} \frac{\left(S T^{N}-S T_{1}^{0}\right)}{S T^{N}} \\
T C V^{2} & =W_{2} \frac{\left(S T^{N}-S T_{2}^{0}\right)}{S T^{N}}
\end{aligned}
$$

where $S T_{1}^{0}$ and $S T_{2}^{0}$ refer to the base case aggregate service consumption in countries 1 and 2, $\mathrm{W}_{1}$ and $\mathrm{W}_{2}$ are economy wide incomes in country 1 and 2 from (2), and again the $\lambda$ terms cancel.

The ratio of the welfare gains in the two countries from liberalization is given by

$$
\frac{T C V^{1}}{T C V^{2}}=\frac{W_{1}}{W_{2}}\left(\frac{S T^{N}-S T_{1}^{0}}{S T^{N}-S T_{2}^{0}}\right)
$$

Noting that in this special case $S T^{N}=S T_{1}^{0}+S T_{2}^{0}$, since there is no quantity response under liberalization, (11) can be rearranged to give the condition that

$$
\frac{T C V^{1}}{T C V^{2}}=1 \text { if } \frac{W_{1}}{W_{2}}=\frac{S T_{1}^{0}}{S T_{2}^{0}}
$$

i.e. the two countries will receive a welfare gain under liberalization of equal size if the ratio of national income and service consumption are the same across the countries.

In this case it is thus simple to construct parameterizations in which both countries will receive benefits from network related service liberalization of equal absolute size, even if one country is smaller or larger than the other and has more or less households. The widely accepted propositions about trade in goods, the division of gains and country relative size thus seem not to apply to this case in the same way. 


\section{The Gains from Liberalization in a Two Service Model}

While illustrating a case where the gains from network related service trade liberalization between countries can be of equal absolute size, the discussion in the previous section nonetheless embodies some strongly simplifying model features. Liberalization is simply treated as a connection of two separate country networks, and so unchanged relative services to goods prices in each country characterize a liberalization scenario. Also, because the network externality effect is multiplicative in utility, no real effects accompany liberalization; consumption and production of network related services remains unchanged in the new integrated network equilibrium, while household utility changes due to expanded network size.

One can modify these assumptions by extending the above framework and seeing if similar results can be obtained, but numerical simulation is needed to investigate its properties since model solutions are no longer analytic. To do this, we separately consider two different types of services; those relating to domestic and to internationally transmitted services (message communications). In the process, we give governments the power to tax these two types of services when purchased in their own country. A higher tax rate on international rather than on domestic communications can be thought of as reflecting regulation of internationally linked network service transactions. Liberalization in this case involves lowering barriers to international communication, and is reflected in reduced tax rates in all countries on purchases of international network related services. This form of services liberalization, unlike that considered in the previous section, generates relative price effects and, hence, quantity responses.

We use specific functional forms for this purpose; in this case a constant elasticity of transformation (CET) function to describe the transformation of endowments into goods and services, but now one which incorporates two service types $S_{1}$ and $S_{2}$, one of which is supplied domestically and the other internationally, i.e.

$$
Y_{n}=\left(\eta_{n}^{1} G_{n}^{\frac{\sigma_{n}-1}{\sigma_{n}}}+\eta_{n}^{2} S_{1}^{\frac{\sigma_{n}-1}{\sigma_{n}}}+\eta_{n}^{3} S_{2}^{n} \frac{\sigma_{n}-1}{\sigma_{n}}\right)^{\frac{\sigma_{n}}{\sigma_{n}-1}}
$$


where $Y_{n}$ is the fixed resource endowment of county n, $G_{n}$ is goods production in country n, $S_{1}^{n}$ is production of service type 1 in country $\mathrm{n}$, and $S_{2}^{n}$ is production of service type 2 in country n. $\eta_{n}^{1} \eta_{n}^{2}$ and $\eta_{n}^{3}$ are share parameters in production, and $\sigma_{n}$ is the country $\mathrm{n}$ elasticity of transformation.

The value of production of goods and services in country $n$ is now given by

$$
W_{n}=P_{g} G_{n}+P_{n}^{s_{1}} S_{1}^{n}+P_{n}^{s_{2}} S_{2}^{n}
$$

and maximizing the value of production subject to the CET function (13) implies supply functions for country $\mathrm{n}$ for the two types of services

$$
\begin{aligned}
& S_{1}^{n}=G_{n}\left(\frac{\eta_{n}^{2}}{\eta_{n}^{1}} \frac{P_{g}}{P_{n}^{S_{1}}}\right)^{\sigma_{n}} \\
& S_{2}^{n}=G_{n}\left(\frac{\eta_{n}^{3}}{\eta_{n}^{1}} \frac{P_{g}}{P_{n}^{S_{2}}}\right)^{\sigma_{n}}
\end{aligned}
$$

Each household in each country again derives utility from consumption of goods, but now also from the two types of services. These households also receive externality benefits from the consumption of network related services by other households along both the home and international networks.

We again use Cobb-Douglas preferences for each household, but now of the form ${ }^{8}$

$$
U_{n}^{h}=G_{n}^{h^{\alpha_{1}^{h}}}\left(S_{1}^{n, h}\left(\sum_{h} S_{1}^{n, h}\right)\right)^{\alpha_{2}^{h}}\left(S_{2}^{n, h}\left(\sum_{n} \sum_{h} S_{2}^{n, h}\right)\right)^{\alpha_{3}^{h}}
$$

Here $\mathrm{n}$ superscripts and subscripts refers to countries, and the superscript $\mathrm{h}$ refers to the households within country n. $U$ is utility, $G$ is consumption of goods, and $S_{1}$ and $S_{2}$ are consumption of the two service types (domestic and international). As before, household utility increases when country service networks are more fully joined, but these effects now operate differently in the home and international markets.

Each household again receives a fixed share of country income

$$
I_{n}^{h}=\theta_{n}^{h} W_{n}^{h}
$$

and this income is spent on purchasing goods and services. Household budget constraints now imply that

\footnotetext{
${ }^{8}$ The $\lambda$ term from the previous section does not appear here. The externality summation term multiplies the separate $S_{1}$ and $S_{2}$ terms rather than all utility.
} 


$$
I_{n}^{h}=P^{g} G_{n}^{h}+P_{n}^{S_{1}} S_{1}^{n, h}+P_{n}^{S_{2}} S_{2}^{n, h}
$$

and demands for goods and services by each household are derived from maximization of Cobb-Douglas household utility functions subject to the household budget constraints (19).

These give goods demands as:

$$
G_{n}^{h}=\frac{\alpha_{1, n}^{h} \cdot I_{n}^{h}}{P_{g}}
$$

and demands for the two types of services as

$$
\begin{aligned}
& S_{1}^{n, h}=\frac{\alpha_{2, n}^{h} \cdot I_{n}^{h}}{P_{n}^{s_{1}}} \\
& S_{2}^{n, h}=\frac{\alpha_{3, n}^{h} \cdot I_{n}^{h}}{P_{n}^{s_{2}}}
\end{aligned}
$$

Markets for goods and services again clear at country level in equilibrium, i.e.

$$
\begin{aligned}
G_{n} & =\sum_{h} G_{n}^{h} \\
S_{1}^{n} & =\sum_{h} S_{1}^{n, h} \\
S_{2}^{n} & =\sum_{h} S_{2}^{n, h}
\end{aligned}
$$

Taxes charged by national governments on $S_{2}$ purchased at home can be incorporated into this framework, and distort the relative prices of both services and goods, and among services, reducing purchases of externality generating international services.

Table 1 presents parameterizations we have used in a numerical example showing the impacts of network related services liberalization in this two services type model. Country 2 has double the resources of country 1 at 1000 rather than 500. We consider 3 households in country 1 and 5 in country 2, with identical preferences within countries. We consider liberalization to be a removal of a pre existing 50 percent tax on international services in both countries.

As the results in Table 1 show, we can construct cases, such as that in the first specification where, as before, the absolute value of the gains from liberalization in network related services are similar across the two countries. It is also possible with a change in specification to construct a case where the gains to the two countries go mainly to the large country (opposite to trade in goods), as in the second specification. 
In this more realistic but more complex world, then, the theme is the same as above; namely that with network externalities and cross country service liberalization, there is no presumption (as with goods) that the benefits of liberalization will accrue disproportionately to the small country. Per capita effects and country size seemingly once again operate in opposite directions.

Table 1

Model specifications of the two services type model yielding country gains from liberalization of similar size across countries and larger gains for the larger country.

\begin{tabular}{|c|c|c|}
\hline & $\begin{array}{l}\text { Specification yielding } \\
\text { similar size country } \\
\text { gains }\end{array}$ & $\begin{array}{l}\text { Specification yielding } \\
\text { the majority of the } \\
\text { gains to the larger } \\
\text { country }\end{array}$ \\
\hline $\begin{array}{l}\text { Production } \\
\text { Resources } \\
\text { Transformation frontier shares and } \\
\text { elasticities }\left(G, S_{1}, S_{2}\right)\end{array}$ & $\begin{array}{l}\text { Country } 1 \quad Y_{1}=500 \\
\text { Country } 2 Y_{2}=1000 \\
\eta_{1}=0.5 ; \eta_{2}=0.25 \\
\eta_{3}=0.25 \\
\sigma=-0.75\end{array}$ & $\begin{array}{l}\text { Country } 1 \quad Y_{1}=500 \\
\text { Country } 2 \quad Y_{2}=1000 \\
\eta_{1}=0.5 ; \eta_{2}=0.25 \\
\eta_{3}=0.25 \\
\sigma=-0.75\end{array}$ \\
\hline $\begin{array}{l}\text { Demand ( } 3 \text { households in country } 1 \text { and } 5 \\
\text { in country } 2 \text {, with identical preferences } \\
\text { within countries) } \\
\text { Demand side shares }\left(G, S_{1}, S_{2}\right)\end{array}$ & $\begin{array}{l}\text { Country } 1 \quad \alpha_{1}=0.2 ; \\
\alpha_{2}=0.2 ; \alpha_{3}=0.6 ; \\
\text { Country } 2 \alpha_{1}=0.3 ; \\
\alpha_{2}=0.4 ; \alpha_{3}=0.3 ;\end{array}$ & $\begin{array}{l}\text { Country } 1 \alpha_{1}=0.4 \\
\alpha_{2}=0.4 ; \alpha_{3}=0.2 \\
\text { Country } 2 \alpha_{1}=0.2 \\
\alpha_{2}=0.2 ; \alpha_{3}=0.6\end{array}$ \\
\hline $\begin{array}{l}\text { Taxes } \\
\text { Pre liberalization (country tax rates on } \mathrm{S}_{2} \text { ) } \\
\text { Post liberalization (country tax rates on } \mathrm{S}_{2} \text { ) }\end{array}$ & $\begin{array}{l}\mathrm{t}_{1}=0.5 ; \mathrm{t}_{2}=0.5 \\
\mathrm{t}_{1}=0.0 ; \mathrm{t}_{2}=0.0\end{array}$ & $\begin{array}{l}\mathrm{t}_{1}=0.5 ; \mathrm{t}_{2}=0.5 ; \\
\mathrm{t}_{1}=0.0 ; \mathrm{t}_{2}=0.0 ;\end{array}$ \\
\hline $\begin{array}{l}\text { Country welfare gains from } \\
\text { liberalization } \\
\text { (Hicksian CV as fraction of GDP in the } \\
\text { parenthesis) }\end{array}$ & $\begin{array}{l}\mathrm{EV}_{1}=66.4(0.133) \\
\mathrm{EV}_{2}=66.6(0.067)\end{array}$ & $\begin{array}{l}\mathrm{EV}_{1}=25.5(0.051) \\
\mathrm{EV}_{2}=133(0.133)\end{array}$ \\
\hline
\end{tabular}




\section{The size of the gains from liberalization in service network}

Having argued that the country division of the gains from international liberalization in network related services will typically differ from that for trade in goods, we next proceed to a discussion of the size of the gains from such liberalization.

We analyze the size of the gains from liberalization in a cross country policy game by comparing Nash equilibrium and free trade outcomes. The network related service policy game differs from a conventional tariff game (Johnson (1954), Gorman (1957)) in which both countries apply tariffs to their own imports. In this game, both countries have the ability to tax service flows between countries; the origin country through regulation of the service flow as it leaves its own border, and the destination country through regulation of flows from its own border onward within the country of the eventual recipient of the network related service ${ }^{9}$. Thus, in the two country case four tax rates $t_{i}^{j}$ are involved in the game; the tax rates charged by country $j$ on services originating in country $i$.

We use our two service type model set out in section III above, with the further difference here being that tax rates charged by the two countries on network related services are endogenously determined in a Nash equilibrium rather than set exogenously. In the process, we determine the two country two tax rate reaction functions

$$
\begin{aligned}
& t_{2}^{1}=t_{2}^{1}\left(t_{1}^{1}, t_{1}^{2}, t_{2}^{2}\right) \\
& t_{1}^{1}=t_{1}^{1}\left(t_{2}^{1}, t_{1}^{2}, t_{2}^{2}\right) \\
& t_{1}^{2}=t_{2}^{1}\left(t_{2}^{1}, t_{1}^{1}, t_{2}^{2}\right) \\
& t_{2}^{2}=t_{2}^{1}\left(t_{2}^{1}, t_{1}^{1}, t_{1}^{2}\right)
\end{aligned}
$$

At a Nash equilibrium of the policy game, we have a fixed point for these reaction functions (26)-(29).

$$
t_{j}^{i, *}=t_{j}^{i}\left(t_{i}^{i, *}, t_{i}^{j, *}, t_{j}^{j, *}\right)
$$

\footnotetext{
${ }^{9}$ A non cooperative outcome thus corresponds to a breakdown of the present revenue sharing agreements discussed in ITU (1994).
} 
To provide a point of comparison to tariff games in goods trade, we also compute Nash equilibria in a two country tariff game in which $S_{2}$, instead of being a network related service, is treated as a conventional commodity, much like G. In this calculation, all share and elasticity parameters are as in the two service type model calculations reported on in Table 1, and in a Nash equilibrium tariff rates on imports are determined by commodity and by the country of source. In this case, levels of only two instruments (tariffs on imports by each country) are endogenously determined, rather than four instruments as in the network service case.

Table 2 lists both specifications and results from both of these calculations, and compares Nash equilibrium outcomes to those under no intervention (free trade in the goods trade model). Because of the network externality accruing to own country residents, origin countries have an incentive to subsidize own consumption of internationally traded services, but destination countries have an incentive to apply a significant tax due to revenues transferred from abroad under the tax.

As a $\%$ of national income, results in Table 2 suggest that the welfare gains from moving to no intervention (the analogue of free trade) are larger in the two service type model than in the trade model. On the basis of these calculations we suggest that country size seems to play a more pronounced role in the services case than in the goods trade tariff war. The gains from liberalization are the considerably larger in the network related services case than in the goods case with a similar parametric specification. 


\section{Table 2}

Differences in the welfare gains from liberalization in a tradeable goods model and a service networks model, relative to a Nash equilibrium.

\begin{tabular}{|c|c|c|}
\hline & $\begin{array}{l}\text { Services related network } \\
\text { model ( } 2 \text { service type) }\end{array}$ & Trade in goods model \\
\hline $\begin{array}{l}\text { Production } \\
\text { Resources Endowment } \\
\text { Transformation elasticities } \\
\text { Transformation shares }\left(\mathrm{G}, \mathrm{S}_{1}, \mathrm{~S}_{2}\right)\end{array}$ & $\begin{array}{l}\text { Country } 1 \quad Y_{1}=500 \\
\text { Country } 2 Y_{2}=1000 \\
\eta_{1}=0.5 ; \eta_{2}=0.25 \\
\eta_{3}=0.25\end{array}$ & $\begin{array}{l}\text { Country } 1 \quad Y_{1}=500 \\
\text { Country } 2 Y_{2}=1000 \\
\eta_{1}=0.5 ; \eta_{2}=0.25 \\
\eta_{3}=0.25\end{array}$ \\
\hline $\begin{array}{l}\text { Demand } \\
\text { Demand side shares }\left(G, S_{1}, S_{2}\right)\end{array}$ & $\begin{array}{l}\text { Country } 1 \alpha_{1}=0.4 \\
\alpha_{2}=0.4 ; \alpha_{3}=0.2 ; \\
\text { Country } 2 \alpha_{1}=0.2 \\
\alpha_{2}=0.2 ; \alpha_{1}=0.6\end{array}$ & $\begin{array}{l}\text { Country } 1 \quad \alpha_{1}=0.4 \\
\alpha_{2}=0.4 ; \alpha_{1}=0.2 ; \\
\text { Country } 2 \alpha_{1}=0.2 \\
\alpha_{2}=0.2 ; \alpha_{3}=0.6 \\
\end{array}$ \\
\hline $\begin{array}{l}\text { Nash Equilibrium Tariff Rates } \\
\text { (tariff rates on goods and tax } \\
\text { rates on services) }\end{array}$ & $\begin{array}{l}t_{1}^{1}=-27.2 \% ; t_{2}^{1}=45.4 \% \\
t_{2}^{2}=-12.6 \% ; t_{1}^{2}=26.8 \%\end{array}$ & $\begin{array}{l}\text { Country } 1 \text { tariff: } 29.9 \% \text {; } \\
\text { Country } 2 \text { tariff: } 23.6 \% \text {; }\end{array}$ \\
\hline $\begin{array}{l}\text { Welfare gain in no intervention } \\
\text { case (free trade) compared to } \\
\text { Nash equilibrium } \\
\text { (Hicksian EV or CV as a \% of } \\
\text { national income) }\end{array}$ & $\begin{array}{l}\mathrm{EV}_{1}=39.3 \\
\mathrm{EV}_{2}=43.6\end{array}$ & $\begin{array}{l}\mathrm{EV}_{1}=7.0 \\
\mathrm{EV}_{2}=1.0\end{array}$ \\
\hline
\end{tabular}




\section{Empirical Analysis of Global Telecoms Liberalization}

We have also used the two service type model set out above to analyze the implications of global liberalization in telecoms using an empirically based specification of the modelling approach above. For these purposes, we consider a global four region telephone service network consisting of Canada, Europe, USA and the Rest of the World (ROW). We use this to compute the global welfare gains from liberalization adopting the network related service model presented above. We also analyze the role played by the relative sizes of domestic and global networks in determining the division of gains, using data on the volume of cross-border telephone calls, and the relative size of caller and recipient regions. The size of the domestic network in Canada, for instance, is smaller than that of the USA, even though both countries have inter connected domestic and international networks. European countries have a well developed domestic network, while networks elsewhere in the world are, on average, not as developed as in the three other regional blocs in the model.

To empirically parameterize the model, we need estimates of preference and technology parameters for each of these regions in the model. In the absence of literature estimates on the relevant elasticities, we have used a value of unity for the transformation elasticities in each region, which we then vary in subsequent sensitivity analysis. The $\lambda$ parameters in preferences determining the strength of the network externality effects are also important, and we have assumed them to be 0.1 in all countries. Using these assumptions, we calibrate share parameters of preference functions and production frontiers using 1991 data on call volumes, implied call prices, and GDP published in the World Telecommunication Development Report (WTDR) (ITU, 1994) and the World Development Report (WDR) (World Bank (1993)).

The 1994 WTDR gives detailed information on the use of telephone networks by country and region, reporting volumes of both international and domestic calls, and revenues generated by the telephone sector in each country, again broken down by domestic and international calls. It also reports total and per capita GDP, as well as other information such as the telephone density and major telephone operating companies in 202 countries and autonomous territories. 
We construct base case data on prices and quantities for our model by dividing WTDR revenues by volumes, using the strong assumption of homogeneity of calls within each group for each country. We use country specific information for Canada and the USA, and use summary statistics for Europe and derive data on the Rest of the World as a residual from world totals minus Canada, USA and Europe. In order to complement this data on trade in network related services to produce a benchmark equilibrium data set for use in calibration, we use merchandise trade data published in the World Development Report, 1993.

Table 4 and its accompanying notes set out the details of how we have manipulated basic data to obtain a model admissible benchmark equilibrium data set for model calibration ${ }^{10}$. We use this for counterfactual equilibrium analysis in which we reduce the differential pricing in all regions between international and domestic calls by one half, and then perform sensitivity tests in order to assess the robustness of model results to alternative values of elasticity parameters in production.

Calibrating our two service model to the information in table 4 yields the calibrated model parameters reported in table 5. The share parameters in the demand functions are computed using income and price information applied to Cobb-Douglas demand functions, with the sum of share parameters constrained to equal one. Share parameters in the production possibility frontier are computed using information on the value of goods and two types of services produced, and the elasticities of transformation by region. Both sets of share prameters are dominated in their first component by GNP which is large relative to the service categories.

Table 4

Base year (1991) data used for calibration of empirically based service telecom model

\footnotetext{
${ }^{10}$ Several features of this data set are important for our experiments and results. One is that prices for international calls are sharply above prices for domestic calls (this situation has changed since 1991). Another is that domestic calls are higher in North America than in Europe and ROW, reflecting the higher share of intra continental (e.g. LA/NY) calls to local calls in this region.
} 


\begin{tabular}{|c|c|c|c|c|c|c|c|c|c|c|}
\hline & $\mathrm{GDP}^{1}$ & $\mathrm{VS}^{2}$ & $\mathrm{VS}^{2}$ & $\mathrm{PS}^{3}$ & $\mathrm{PS}^{4}$ & $\mathrm{~S}_{1}{ }^{5}$ & $\mathrm{~S}_{2}{ }^{6}$ & $\mathrm{M}^{7}$ & $\mathrm{E}^{7}$ & $\mathrm{GE}^{7}$ \\
\hline Canada & 592.80 & 7.97 & 3.41 & 0.09 & 4.72 & 8851 & 724 & 117.60 & 124.80 & -7.20 \\
\hline Europe & 7441.00 & 124.16 & 28.94 & 0.07 & 1.46 & 177377 & 19870 & 95.10 & 120.90 & -25.80 \\
\hline USA & 5672.600 & 83.88 & 37.68 & 0.09 & 3.73 & 93196 & 10111 & 506.20 & 397.70 & 108.50 \\
\hline ROW & 8064.70 & 85.51 & 42.12 & 0.03 & 4.13 & 285043 & 10200 & 2789.30 & 2693.20 & 96.10 \\
\hline
\end{tabular}

Source: World Telecommunication Union Development Report 1994, ITU, Geneva.

1. GDP, gross domestic product (in billions of US \$s) is from table 1 of WTDR.

2. VS1 value of service type 1, VS2 value of service type 2, are derived from table 11 of

WTDR and the split between two is based on information in table 4 of WTDR.

3. PS1 are prices of domestic calls reported in table 11 of WTDR.

4. PS2 are prices of foreign calls obtained by dividing VS2 by S2.

5. $S_{2}$ number of international calls, reported in table 13, A-39, WTDR.

6. $S_{1}$ is number of domestic calls obtained by dividing VS1 by PS1.

7. $\mathrm{M}$ and $\mathrm{E}$ are values of merchandise imports and exports obtained from the World Development

Report (World Bank, 1993), Table 14, pp. 264-265. GE is balance of merchandize trade,

M-E.

Table 5

Calibrated share parameters in the empirically based telecom model

\begin{tabular}{|c|c|c|c|c|}
\hline & Canada & Europe & USA & ROW \\
\hline$\alpha_{1}$ & 0.962 & 0.96 & 0.958 & 0.969 \\
\hline$\alpha_{2}$ & 0.013 & 0.16 & 0.014 & 0.01 \\
\hline$\alpha_{3}$ & 0.024 & 0.027 & 0.027 & 0.021 \\
\hline$\eta_{1}$ & 0.838 & 0.831 & 0.843 & 0.830 \\
\hline$\eta_{2}$ & 0.069 & 0.064 & 0.068 & 0.075 \\
\hline$\eta_{3}$ & 0.093 & 0.105 & 0.089 & 0.095 \\
\hline
\end{tabular}

Note: $\alpha$ s refer to consumptions, $\eta$ s refer to production shares. Subscripts 1,2 and 3 denote nontelecom GDP, domestic phone calls, and international phone calls respectively.

Table 6 reports regional welfare benefits from liberalization in international network related services using this model specification, where the price differential in all regions between domestic and international phone rates is halved. Results show gains for all regions 
but in proportional terms these are comparable across the smallest and largest region, confirming the conjecture we offered earlier regarding the country division of the gains from liberalization in services and the difference relative to goods liberalization. Changes in the consumption of international service are also the largest in the smaller country.

Table 6

Regional benefits from global liberalization of telecoms services (basesd on 1991 data)

Welfare gains from liberalization by region (Hicksian EV as percentage of GDP)

\begin{tabular}{|c|c|c|c|}
\hline Canada & Europe & US & ROW \\
\hline 4.2 & 4.1 & 4.4 & 3.9 \\
\hline
\end{tabular}

Table 7

Sensitivity Analysis of Regional Welfare Results for international telecom service liberalization (Welfare effects of Hicksian EV as percentage of GDP)

\begin{tabular}{|l|c|c|c|}
\hline Countries & Base case & $\begin{array}{c}\text { Doubling } \\
\text { transformation } \\
\text { elasticities in all } \\
\text { regions }\end{array}$ & $\begin{array}{c}\text { Halving }^{11} \\
\text { transformation } \\
\text { elasticity }\end{array}$ \\
\hline Canada & 4.2 & 4.2 & 4.0 \\
\hline Europe & 4.1 & 3.9 & 4.2 \\
\hline USA & 4.4 & 4.7 & 4.0 \\
\hline ROW & 3.9 & 4.0 & 3.8 \\
\hline
\end{tabular}

We have performed some limited sensitivity analysis using this model to explore ranges of welfare estimates by region as we vary production side elasticities (the model demand side is Cobb-Douglas). Results are reported in Table 7, and the money metric welfare effects by region are little affected as elasticities of transformation change.

11 Base case values are -1.25. 


\section{Conclusion}

In this paper we explore the implications of international liberalization of network related services, such as telecoms. We argue that in the presence of network externalities, larger per capita benefits accrue to residents of smaller countries on expanding international networks, which roughly offsets differences in numbers of residents (country size). Unlike for trade in goods, gains from liberalization can be of approximately equal absolute size across small and large countries.

We first show this for a simple case , and explore this further numerically for more complex structures, including for an empirical model implementation to global telcoms liberalization for the US, Europe, Canada and the rest of the world. This theme that the division of gains does not relate to country size in the sameways as for the case of liberalization of goods trade prevails across all model calculations. We also show larger gains from liberalization relative to a Nash equilibrium in a network related service model than in a comparable goods model. 


\section{References:}

Cairncross F. (1997), The Death of Distance :How the Communications Revolution will Change Our Lives Orion Business, London.

Choi J. P. (1994) Network Externality, compatibility, choice, and planned obsolescence, Journal of Industrial Economics, vol. XLII ,June , 167-182.

Economides N. (1996) Network Externatilities, complementarities, and invitations to enter, European Journal of Political Economy, vol. 12, pp.211- 233.

Economides N. (1996) Economics of Networks, International Journal of Industrial Organization, vol. 14, pp. 673-699.

GAMS Development Corporation (1996) GAMS: The Solver Manuals, Washington D.C.

Gorman W. M.(1958) Tariffs, Retaliation and the Elasticity of Demand for Imports, Review of Economic Studies, June 25(3), pp. 133-62.

Harris R. G. (1995) Trade and Communication Costs, Canadian Journal of Economics, Special Issue November.

International Telecommunication Union (1994) World Telecommunication Development Report, Geneva.

Johnson H. G.(1953-54) Optimal tariffs and Retaliation, Review of Economic Studies, 21(2), pp.142-43.

Katz M. L and Shapiro C. (1986) Technology Adoption in the Presence of Network Externalities, Journal of Political Economy, vol. 94, no.4, pp. 822- 841.

Katz M. L and Shapiro C. (1985) Network Externalities, Competition and Compatibility, Americal Economic Review, Vol. 75. no. 3, pp. 424-440.

Liebowitz S.J., Margolis S. E. (1994) Network Externality: An Uncommon Tragedy, Journal of Economic Perspective, vol. 8, No.2, Spring, pp. 133-150.

Meade J.E. (1952) External Economies and Diseconomies in a competitive situation, Economic Journal, Vol. 62, March.

Melvin J. R. (1989) Trade in Producer Services: A Heckscher-Ohlin Approach, Journal of Political Economy, 97(5) pp. 1180-96.

World Bank (1993), World Development Report, Oxford University Press, Washington D.C. 